\title{
Preparation and Investigation of PVA/Cu Nanoparticles by Eco-friendly Electrochemical Method
}

\section{Tarek Fahmy}

Mansoura University Faculty of Science

Ahmed Habib ( $\square$ ahmedhabib@mans.edu.eg)

Mansoura University Faculty of Science https://orcid.org/0000-0001-9506-4186

\section{Afaf Sarhan}

Mansoura University

\section{Research Article}

Keywords: Polyvinyl alcohol (PVA), Copper, Nanoparticles, Band gap, Refractive index.

Posted Date: February 25th, 2022

DOI: https://doi.org/10.21203/rs.3.rs-1368795/v1

License: (c) (i) This work is licensed under a Creative Commons Attribution 4.0 International License.

Read Full License 


\title{
Preparation and Investigation of PVA/Cu Nanoparticles by Eco-friendly Electrochemical Method
}

\author{
T FAHMY, A HABIB* and A SARHAN \\ Polymer Research Group, Physics Department, Faculty of Science, Mansoura University, ET- \\ 35516, Mansoura, Egypt \\ *Author for correspondence ahmedhabib@mans.edu.eg
}

\begin{abstract}
Polyvinyl alcohol (PVA) /Cupper nanocomposite samples have been prepared electrochemically with different times of electropolymerization process. The characterization of prepared samples has been carried out using different techniques such as, X-ray diffraction, FTIR and UV-Vis spectroscopy. XRD patterns showed that, with increasing Cupper nanoparticles (CuNPs) content, the crystal size (D hkl) values are decreased whereas the internal strain values of $\mathrm{PVA} / \mathrm{Cu}$ nanocomposite samples are increased, indicating that a crystal distortion and defects have been occurred in PVA matrix. FTIR spectroscopy revealed that the incorporation of CuNPs induced modifications in the PVA structure. The presence of the characteristic surface plasmon resonance peak at $773 \mathrm{~nm}$ in the absorption spectra of the PVA/CuNPs composite samples confirmed the formation of copper nanoparticles. Analysis of UV-Vis spectra showed that the indirect and direct optical bandgap energies of PVA/CuNPs samples decreased with increasing the CuNPs content. On the other hand, an increase in the refractive index of PVA is observed with increasing concentration of CuNPs. The decrease in the band gap and the increase in conductivity due to the formation of localized electronic states in the PVA host matrix due to the introduction of copper nanoparticles can be related.
\end{abstract}

Keywords: Polyvinyl alcohol (PVA), Copper; Nanoparticles, Band gap, Refractive index.

Email: ahmedhabib@mans.edu.eg

\section{Introduction}

Polyvinyl alcohol (PVA) is a water-soluble crystalline vinyl polymer with hydroxyl groups $(-\mathrm{OH})$ attached to the carbon atoms of the backbone of a long-chain molecule. PVA exhibits properties such as, biodegradability, biocompatibility, non-corrosiveness, excellent optical transmission and thermal and chemical stability. Hydrogen bonding between PVA and 
other substances is facilitated by the presence of $-\mathrm{OH}$ on the carbon backbone of PVA, and these bonds help in the formation of the complexes or blending with other polymers [1-3]. PVA is of great interest because it is relatively cheap, widely accessible, contains many volatile functional groups, has hydrophilic properties, excellent charge storage capacity and it has large dielectric strength. These characteristics, especially their optical properties such as the energy gap and refractive index, enhance their industrial and technological uses as surfactants, adhesives, drug delivery, coating material, a supercapacitor component, a solar cell component, optical sensors and nonlinear optical devices [4-6].

Dopant materials as fillers in polymer matrices are essential in many respects due to their low cost and simple production, their high ability to control thermal conductivity and thermal expansion, and their impressive novel electrical and optical properties [7,8]. Recently, investigation of polymer composites with various nanoparticles, including metals has gained intense focus due to the excellent features when compared with the host polymer [9-11]. Metalpolymer nanocomposites are an important topic because they combine the features of polymers with those of metals. It has also attracted great interest due to its outstanding optical, electrical and catalytic properties, which have potential applications in various fields such as bioengineering, electronics and photonics [12,13]. The improvement in the properties of these materials is due to the interaction between the polymer matrix and the nanoparticles. Addition of nanoparticles to a polymer matrix provides low cost, ease of device fabrication, improved nanoparticle lifetime, nanoparticle surface modification by passivation defect states, and tunable optical and electronic properties.

Currently, nonlinear optical properties are a vital topic for many investigations due to their potential applications in computing and optical signal processing. Such investigations of linear and nonlinear optical parameters enable us to appropriately fabricate materials at the molecular level for specific applications such as, optoelectronic devices. Studying the optical constants of materials (extinction coefficient and optical bandgap) is vital for examining electronic band structure, atomic structure and electrical properties [14]. Recently, materials with high nonlinear optical properties (NLO) have received a lot of attention due to their widespread use in many critical applications such as, photovoltaic solar cells, optoelectronic and photonic devices, light-emitting diodes (LEDs), optical signal processing, optical communications, optical witching, optical sensors and optical power reduction [15-18]. 
Metallic nanoparticles exhibit exceptional and tunable optical properties as a result of surface plasmon resonance (SPR). Due to the collective coherent excitation of free electrons in the conduction band of these particles these metal particles are characterized by high absorption and scattering. SPR in metallic nanoparticles is very important for many different applications, including focusing of light, sub-wavelength photonics, near-field optical microscopy, and molecular sensing. SPR phenomenon is also important for third-order nonlinear optical susceptibility. Thus, plasmonic materials are critical and unique for optoelectronic devices such as ultrafast photonic switches $[19,20]$. The present article is devoted to investigate the effect of $\mathrm{Cu}$ nanoparticles on the structure and optical properties of PVA.

\section{Experimental}

\section{Materials}

Poly (vinyl alcohol) (PVA) is a commercial product with molecular weight $\sim 72000$ is purchased from Merck, (Germany). Copper plates with dimensions of (2 mm x $20 \mathrm{~mm}$ x 40 $\mathrm{mm})$ and platinum rectangular sheet with dimension of $(0.5 \mathrm{~mm} \times 20 \mathrm{~mm} \times 40 \mathrm{~mm})$ are supplied from Sigma- Aldrich of purity $99.995 \%$. Copper and platinum plates are used as working electrode (anode) and counter electrode (cathode), respectively.

\section{Methods}

\section{Preparation method}

PVA-Cu complexes are prepared electrochemically in an aqueous acidic medium. The electrochemical-oxidation is occurred at fixed potential of 1.5 volt in a one compartment electrochemical cell. Electrolytic solutions were produced by dissolving 1 wt \% PVA into $1 \%$ acetic acid, and stirred for $48 \mathrm{~h}$. $\mathrm{Cu}$ (anode) and pt (cathode) plates were separated by $5 \mathrm{~cm}$ in the electrolytic solution and contacted to a proper changing resistor. The temperature of the reaction mixture was maintained at $300 \mathrm{~K}$ with constant stirring. This experiments were carried out for different time to reach the equilibrium concentration of the metal ion in the electrolytic solution. The centrifuge (Model: PLC-012E) was operated at speed $4000 \mathrm{rpm}$ per $10 \mathrm{~min}$ and the product was filtered before used to eliminate any impurities.

\section{Characterization tools}

X-ray diffraction pattern of all samples is carried out using Rigaku Ultima IV diffractometer with $\mathrm{Cu}-\mathrm{K} \alpha$ radiation, $(\lambda=1.5418 \AA$ at $40 \mathrm{kV})$. FT-IR spectra are carried out 
between 400 and $4000 \mathrm{~cm}^{-1}$ by FT-IR spectroscopy, Mattson, UK. UV-Vis spectra are recorded between 200 and $800 \mathrm{~nm}$ using ATI Unicom UV-Vis. spectrophotometer with the aid of ATI Unicom UV-Vis. vision software V 3.20.

\section{Results and discussion}

\section{X-ray diffraction}

The formation of CuNPs in PVA host matrix can be confirmed using X-ray diffraction analysis. The microstructure of pure and PVA/CuNPs is achieved using X-ray diffraction (XRD) measurements, as shown in Fig. 1a. The strong intermolecular interaction between PVA chains through hydrogen bonding shows many diffraction peaks indicating the semi-crystalline nature of PVA. Sharp crystalline reflection with a strong maximum at $2 \theta=19.74^{\circ}(\mathrm{d}=4.56 \AA)$ and a shoulder at $2 \theta=22.86^{\circ}(\mathrm{d}=3.96 \AA)$, revealing that the crystalline atactic PVA is present [21]. The two maxima at $19.74^{\circ}$ and $22.86^{\circ}$ correspond to the (101) and (101) reflections, respectively. Moreover, XRD pattern of PVA is characterized by two broad peaks at $11.02^{0}$ and $40.51^{0}$. Our data is consistent with which reported for pure PVA previously [22]. On the contrary, XRD pattern of PVA/CuNPs composite samples showed four reflection peaks at $8.29^{\circ}$, $9.96^{\circ}, 12.10^{\circ}$ and $16.83^{\circ}$. Moreover, the existence of a broad peaks at about $2 \theta=31.25^{\circ}$ and $49.82^{\circ}$ are attributed to the (111) and (200) planes of the fcc structure of the CuNPs (JCPDS card No. 4-0836), whereas, the peaks at $31.52^{\circ}$ and $36.26^{\circ}$ are attributed to the (111) and (111) of $\mathrm{Cu}_{2} \mathrm{O}$ (JCPDS card No.03-0892), respectively [23-25]. The production of $\mathrm{Cu}_{2} \mathrm{O}$ particles is attributed to the instability of the copper nanoparticles, indicating that many of the copper particles are oxidized in air after sample preparation during the drying process because of the hydrophilic nature of PVA [26]. In addition, it was observed that the position of the PVA reflection peak (at $19.74^{\circ}$ ) does not significantly affected by the incorporation of copper nanoparticles. Also, a decrease in the XRD peak intensity as well as an increase in its broadening was also observed for the $\mathrm{PVA} / \mathrm{Cu}$ nanocomposites samples. The measurements of both the crystallite size $(D)$ and internal strain $(\varepsilon)$ are performed using Debye-Scherrer formula as follows [27]:

$$
D_{h k l}=\frac{0.9 \lambda}{\beta_{h k l} \cos \theta}
$$




$$
\varepsilon=\frac{\beta_{h k l}}{4 \tan \theta}
$$

Where $D_{h k l}$ is the particle diameter, $\lambda$ is the wavelength of X-ray and equals $1.5418 \AA$, $\beta_{h k l}$ is FWHM in radians and $\theta$ is the diffraction angle, respectively. Fig. 1b displays the variation of the crystallite size and internal strain against the electropolymerization time of PVA/Cu nanocomposite samples. Obviously, with increasing the content of CuNPs, the $D_{h k l}$ values are decreased whereas internal strain is increased. This behavior could interpret the effect of the interaction between CuNPs and the PVA matrix. On the other hand, the increased strain expresses an increase in crystal distortion and defects in the PVA/Cu nanocomposite samples as will be explained in the UV part later.

\section{FTIR Spectroscopy}

FTIR spectroscopy is used to confirm the chemical structure of the materials under investigated. Fig. 2a displays FTIR spectrum of pure PVA which is characterized by a broad absorption peak centered at $3334 \mathrm{~cm}^{-1}$ and is attributed to $-\mathrm{OH}$ stretching vibration modes at a hydrogen bond. The absorption peak at 2930 is ascribed to the $\mathrm{CH}_{2}$ asymmetric stretching. A stretching peak related to $-\mathrm{CH}-\mathrm{CH}_{2}$ groups has been appeared at $2825 \mathrm{~cm}^{-1}$ as a shoulder. The absorption peaks at $1665 \mathrm{~cm}^{-1}$ and is attributed to the acetyl $\mathrm{C}=\mathrm{O}$ stretching mode which is explained based on the intra/intermolecular hydrogen bonding with the adjacent $\mathrm{OH}$ group. The band $1430 \mathrm{~cm}^{-1}$ to the $\mathrm{C}-\mathrm{O}-\mathrm{C}$ symmetrical stretching in the acetyl groups exist on the backbone of PVA due to unhydrolyzed acetate groups of PVAc, respectively [28]. The absorption band at $1333 \mathrm{~cm}^{-1}$ is attributed to $\mathrm{CH}_{2}$ out of plane bending, whereas, the bands at 1251 and $1093 \mathrm{~cm}^{-1}$ are related to the interaction between $\mathrm{O}-\mathrm{H}$ bending and $\mathrm{C}-\mathrm{O}$ stretching [29]. The absorption bands $843 \mathrm{~cm}^{-1}$ and 664 are ascribed to unsaturated $\mathrm{CH}_{2}$ stretching and to the $-\mathrm{OH}$ bending vibration of PVA, respectively [30]. The properties of some characteristic absorption bands of PVA both in intensity and location were altered after incorporation of CuNPs into the PVA host matrix as shown in Fig. 2(b-e). The $-\mathrm{OH}$ stretching vibration band has been observed as a broad peak with shift towards lower values of wavenumber (red shift) in PVA/CuNPs compsite samples and the stretching peak of $-\mathrm{CH}-\mathrm{CH}_{2}$ group has been shifted to appear at $2837 \mathrm{~cm}^{-1}$ with shift in the order of $12 \mathrm{~cm}^{-1}$ (blue shift). The band at $1726 \mathrm{~cm}^{-1}$ which is correspond to $\mathrm{C}=\mathrm{C}$ stretching vibration shifted toward $1704 \mathrm{~cm}^{-1}$ (red shift with $22 \mathrm{~cm}^{-1}$ ). The characteristic band of 
$\mathrm{C}=\mathrm{O}$ has been strongly affected and appeared at $1612 \mathrm{~cm}^{-1}$ in PVA/CuNPs composite samples with shift in position of $53 \mathrm{~cm}^{-1}$ (red shift) The absorption band at $1093 \mathrm{~cm}^{-1}$ which is a measure of the crystallization degree of PVA is found to be strongly affected with the addition of CuNPs and it appeared as a broad band at $1077 \mathrm{~cm}^{-1}$ with a shift of $16 \mathrm{~cm}^{-1}$ (red shift). The shift of the absorption bands in PVA/CuNPs composite samples suggests changes in the vibrational energies of PVA chains due to the presence of $\mathrm{Cu}$ nanoparticles. The wavenumber shift shows that PVA facilitates the coordination with $\mathrm{Cu}^{2+}$ species. This coordination has been described by an ester bonding of PVA species to $\mathrm{Cu}$ due to electrostatic attractions elsewhere [31]. Hence, these results confirm the relatively strong bonding associated with the deep interactions of CuNPs within PVA matrix. The absorption bands observed in the range of $500-700 \mathrm{~cm}^{-1}$ of PVA/Cu nanocomposites are attributed to the vibrational modes of both $\mathrm{CuO}$ and $\mathrm{Cu}_{2} \mathrm{O}$ nanostructures [32].

\section{Optical Properties}

UV-visible spectroscopy is used when high-energy lights are absorbed by atoms or molecules, causing electronic excitation. UV-Vis spectroscopy is a straightforward and simple characterization technique to investigate the band structure of the polymer composites or polymer blends [33-35]. Fig. 3a displays the absorption of pure PVA and PVA/Cu nanocomposite samples. The absorption of pure PVA exhibited two bands at 278 and $313 \mathrm{~nm}$ and ascribed to $\pi-\pi^{*}$ and $n-\pi^{*}$ transition, respectively [36]. These bands are due to absorption of carbonyl groups conjugated with one ethylenic group of $-\mathrm{CO}-(\mathrm{C}=\mathrm{C})-$ and $\mathrm{CO}-(\mathrm{C}=\mathrm{C}) 2-$, and to the $-\mathrm{CO}-(\mathrm{C}=\mathrm{C}) 3$-groups, respectively [3]. On the other hand, the samples of PVA/CuNPs beside the characteristic bands of pure PVA showed another broad band at $773 \mathrm{~nm}$. This band is ascribed to the localized surface plasmon resonance (LSPR) band. LSPR arises from the collective oscillation of conduction-band-free electrons in metallic nanoparticles as a result of interactions with light and is very sensitive to the surrounding environment, size and shape. This is because the conduction electrons in the metal are coupled with the electromagnetic field of the incident light. Hence, the conduction electrons will oscillate creating an electric field on the surface with a finite penetration depth $[37,38]$. Similar LSPR has been observed in $\mathrm{PVA} / \mathrm{CuCl}_{2}$ composite samples and chitosan/CuNPs composites [29]. PVA composites incorporated with CuNPs can be used for application in organic optoelectronic devices including polymer solar cells and organic light-emitting diodes. 
Fig. 3b shows the variation of the absorption coefficient $(\alpha=2.3 A / d$, where $A$ is the absorbance and $d$ is the sample thickness) against the photon energy ( $h v$ ) of the incident light. One can observe that, incorporation of CuNPs increases the value of $\alpha$ and all PVA/CuNPs composite samples exhibit high values of $\alpha$ in UV region and very small values in the visible region. The increase of absorption coefficient may be due to the large decrease in the inter-band transitions. Composites of PVA/CuNPs with these properties are therefore potential candidate materials for optoelectronic devices that operate in the region of UV spectrum and can be used in optical windows or as absorbers for solar cells [39]. The absorption edge values are computed by extrapolating the linear plot to $\alpha=0$ at the linear region as shown in Fig. $3 \mathrm{~b}$ and tabulated in Table 1. It is found that the absorption edge is decreased with increasing CuNPs content in the PVA matrix. The redshift of absorption edge confirmed that the optical bandgap of the PVA films has been changed after doping with CuNPs.

The Urbach energy $\left(E_{U}\right)$ is related to the structural disorder in low-crystalline materials. It is associated with expanded local states in the band gap mostly due to the presence of impurities, defects, and non-crystallinity. Band-tail levels in the amorphous structure and disordered materials result from strains in the network sufficient to drive the levels into the forbidden bandgap. It is noteworthy, that the tails decay exponentially in the band gap. The relation between the absorption coefficient $\alpha, E_{U}$ and $h v$ is expressed as follow

$$
\alpha=\alpha_{0} \exp \left(-\frac{h v}{E_{U}}\right)
$$

Where, $\alpha_{0}$ is a pre-exponential factor. Fig. 3c depicts the variation of $\operatorname{Ln} \alpha$ versus $h v$ for pure PVA and PVA/CuNPs samples. It is found that the values of $E_{U}$ are increased with increasing the content of CuNPs as listed in Table 1. The increase in Urbach energy values with increasing CuNPs content in PVA/Cu nanocomposite samples confirms the presence of impurities and defects. The increase in Urbach energy indirectly indicates the growth of the amorphous part of PVA host matrix, i.e., the structure of the PVA/Cu nanocomposite samples has been transferred from crystalline to amorphous with the increase of copper nanoparticles [40]. These results are consistent with the X-ray diffraction data as above, where a decrease in intensity and an increase in the diffraction peak broadness are recorded for PVA/CuNPs samples after addition of CuNPs.

The various values of optical band gap energy $\left(E_{g}\right)$ can be calculated using Tauc's equation as follow: 


$$
(\alpha h v)^{m}=B\left(h v-E_{g}\right)
$$

Where $B$ is a constant and $m$ is a variable equals $1 / 2$ and 2 for allowed indirect and direct allowed transitions, and 3/2 and 3 for forbidden indirect and direct transitions, respectively. Both indirect and direct optical band gap transition can occur near the fundamental absorption edge in the optical materials. Fig. 4(a\&b) displays the variation of $(\alpha h v)^{0.5}$ and $(\alpha h v)^{2}$ versus the photon energy $(h v)$. The indirect $E_{i g}$ and direct $E_{d g}$ optical bandgap values are estimated by extrapolating the linear portion of $(\alpha h v)^{0.5}$ and $(\alpha h v)^{2}$ curves to the photon energy axis at zero absorption as indicated by the solid lines in Fig. 4(a\&b). The calculated values of both $E_{i g}$ and $E_{d g}$ films of pure PVA and $\mathrm{PVA} / \mathrm{Cu}$ nanocomposite samples are reported in Table 1 . It is observed that, $E_{d g}$ values are slightly higher than that of the $E_{i g}$ values. Moreover, the optical bandgap (indirect and direct) values are observed to decrease nonlinearly with increasing the electropolymerizaton time of PVA and copper, as shown in Fig. 5. This means that, the incorporation of CuNPs will increase the defects and disorder in PVA matrix and thus will encourage the segmental motion of PVA chains. Therefore, the electrical conductivity of PVA is expected to improve because the diffusion process of ions between the valence and conduction bands of PVA will be facilitated after the addition of CuNps.

The extinction coefficient $(k=\alpha \lambda / 4 \pi)$ measures the partial loss of electromagnetic energy in the material that arises due to the absorption and scattering of photons per unit the thickness. Fig. 6a illustrates the variation of extinction coefficient versus wavelength pure PVA and PVA/Cu nanocomposite samples. It is observed that the value of $k$ increases with increasing wavelength after the absorption edge. Moreover, the $k$ values of the nanocomposite samples are greater than those of the pure PVA.

Fig. 6b displays the transmittance of pure PVA and PVA/Cu nanocomposite samples. One can observe a sharp increase in the transmittance for all samples in the region where $\lambda<350$ $\mathrm{nm}$. On the other hand, the transmittance of pure PVA in the region $\lambda>350 \mathrm{~nm}$ is increased from $75 \%$ to $99 \%$ with increasing the wavelength, whereas, the transmittance of nanocomposite samples has been decreased to reach $62 \%$. The decrease of the transmittance is due to the increase in the scattered number of incident photons with the increase of the CuNPs content within the PVA matrix. The high transmittance of pure PVA is due to the fact that it does not 
contain free electrons and the conduction band needs a high energy photon. In contrast, the transmittance decreases with the increase in the concentration of ions in PVA/CuNPs samples due to the formation of a layer of covalent bonds between PVA and CuNPs that reduce the transmission of incident light. Some vacant positions in the energy bands will be occupied after the electrons in the outer orbitals move to higher energy levels. Hence, part of the incident light cannot penetrate through it [41]. However, the obtained transmittance values encourage the use of these nanocomposites samples for purposes of optical coating.

Fig. 6c displays the behavior of the reflectance against the wavelength of pure PVA and PVA/CuNPs composite samples. It is observed that the reflectance values of composite samples increase in the lower wavelength region, indicating lower transparency values in the same region. On the other hand, in the visible region the reflectance increases with increasing doping concentration of CuNPs in PVA host matrix. The multiple oscillation peaks in the reflectance spectra are attributed to the photonic interactions between the PVA/CuNPs composite samples and the incident light beam.

The refractive index (n) of transparent materials is an essential parameter in the optical device design. The values of refractive index (n) is estimated calculated using the reflectance (R) according to the following relation, $n=\frac{1+\sqrt{R}}{1-\sqrt{R}}$, where $\mathrm{R}$ is expressed as $R=1-\sqrt{T \exp (A)}$, where $T$ is the transmittance and $A$ is the absorbance [42]. Fig. 7a depicts the variation of refractive index versus the wavelength for pure PVA and PVA/Cu nanocomposite samples. It is noted that, the refractive index decreases rapidly in the lower region of wavelength $(<450 \mathrm{~nm})$ and tends to be constant for pure PVA in the high wavelength region. It is observed that the refractive index values ranged from 1.14 for pure PVA to 2.20 for PVA/Cu nanocomposite. The increase in the refractive index of PVA/Cu nanocomposite samples compared to the pure PVA can be attributed to the increase of free charge carriers and in the reflectivity of the polymer composite samples. Improved refractive index makes this composite to be suitable for antireflective coatings, solar cell manufacturing and design of optical devices [43].

The single oscillator model of Wemple and DiDomenico has been used to analyze the dispersion of the refractive index and to calculate the dispersion energy, $E_{d}$, the single oscillator 
energy, $E_{o}$, the static index of refraction, $n_{o}$ and the static dielectric constant $\left(\varepsilon_{s}\right)$ of the PVA/Cu nanocomposite samples as follows [42]

$$
\begin{array}{cccc}
\left(n^{2}-1\right)=\frac{E_{d} E_{0}}{E_{0}^{2}-(h v)^{2}} & \Rightarrow & \left(n^{2}-1\right)^{-1}=\frac{E_{0}}{E_{d}}-\frac{1}{E_{d} E_{0}}(h v)^{2} \\
n_{0}=\left(1+\frac{E_{d}}{E_{0}}\right)^{1 / 2} & \text { and } & \varepsilon_{s} & =n_{0}^{2}
\end{array}
$$

According to the eqn. (5) the variation of $\left(\mathrm{n}^{2}-1\right)^{-1}$ versus (hu $)^{2}$ for all samples is shown in Fig. $7 \mathrm{~b}$. The slope of these fitted curves equals $\left(-1 / E_{o} E_{d}\right)$ and the intercept equals $\left(E_{o} / E_{d}\right)$, so that the values of $E_{d}, E_{o}$, and $n_{o}$ are calculated and listed in Table 1. The interaction strength between electromagnetic radiation and material is calculated in terms of the optical oscillator force, $\left(f=E_{o} E_{d}\right),[44]$ and listed in Table 1.

The optical spectral momentums $\left(\mathrm{M}_{-1}\right.$ and $\left.\mathrm{M}_{-3}\right)$ of the material give information about the effective number of electrons in the valence band and the effective dielectric constant for the investigated materials and can be estimated using the values of the oscillator parameters $\left(E_{d}\right.$ and $\left.E_{o}\right)$ as follows [45]:

$$
E_{0}^{2}=\frac{M_{-1}}{M_{-3}} \quad \text { and } \quad E_{d}^{2}=\frac{M_{-1}^{3}}{M_{-3}}
$$

Rearranging the eqn. (6a), $\mathrm{M}_{-1}$ and $\mathrm{M}_{-3}$ values for the investigated PVA/Cu nanocomposite samples are determined with the following equation and listed in Table 1.

$$
M_{-1}=\frac{E_{d}}{E_{0}} \quad \text { and } \quad M_{-3}=\frac{M_{-1}}{E_{0}^{2}}
$$

The values of $\mathrm{M}_{-1}$ and $\mathrm{M}_{-3}$ in Table 1 indicate that the $\mathrm{PVA} / \mathrm{Cu}$ nanocomposite samples are characterized by high polarization. The lattice dielectric constant, $\varepsilon_{L}$ (high frequency dielectric constant, $\varepsilon_{\infty}$,) of PVA/CuNPs samples can be calculated using the correlation equation between refractive index and wavelength as follow [42]:

$$
n^{2}=\varepsilon_{L}-\frac{e^{2}}{4 \pi \varepsilon_{0} c^{2}}\left(\frac{N}{m^{*}}\right) \lambda^{2}
$$

Where $e, \varepsilon_{0}, c$ and $\left(N / \mathrm{m}^{*}\right)$ are electronic charge, free space permittivity $\left(8.854 \times 10^{-12} \mathrm{~F} / \mathrm{m}\right)$, light speed and ratio of carrier concentration to effective mass, respectively. Fig. 7c depicts the variation of $n^{2}$ versus $\lambda^{2}$ for PVA/CuNPs samples. The values of lattice dielectric constant $\left(\varepsilon_{L}\right)$ and $\left(\mathrm{N} / \mathrm{m}^{*}\right)$ are calculated by knowing the intercept and slope of fitted curves of Fig. 7c and 
summarized in Table 1. The charge carrier concentration $(\mathrm{N})$ is calculated using the effective mass, $\mathrm{m}^{*}$ which is given by $\mathrm{m}^{*}=0.44 \mathrm{~m}_{\mathrm{o}}$, where $\mathrm{m}_{\mathrm{o}}$ is the electron rest mass and listed in Table 1. It is observed that, the charge carrier concentration is increased with inceasing the content of CuNPs in PVA/Cu nanocomposite samples. The results in Table 1 revealed that, values of lattice dielectric constant $\left(\varepsilon_{L}\right)$ values are higher than the static dielectric constant $\left(\varepsilon_{S}\right)$ values. This difference can be attributed to the contribution of the polarization process that occurs inside the material when light falls on it as well as the increase in the concentration of the free carriers. Also, it is clear from Table 1 that $E_{0}, E_{d}, n_{0}$ and $\varepsilon_{s}$ values are greater than those characteristic of pure PVA. This indicates an increase in the degree of disorder in the PVA structure as well as an increase in charge transfer between PVA macromolecules and CuNPs [46]. The plasma frequency $\left(\omega_{p}\right)$ values of pure PVA and PVA/Cu nanocomposite samples can be estimated based on Drude free-electron model according to the following equation:

$$
\omega_{p}^{2}=\frac{e^{2}}{\varepsilon_{0}}\left(\frac{N}{m^{*}}\right)
$$

Eqn. 8 reveals that the plasma frequency $\left(\omega_{p}\right)$ depends mainly on the charge carrier concentration $(\mathrm{N})$. When the frequency of the incident light $(\omega)$ is equal to the frequency of the plasma $\left(\omega_{p}\right)$, the highest absorption will occur. However, when $\omega<\omega_{p}$, no radiation can propagate (exponential decay), while, when $\omega>\omega_{p}$ oscillation is possible and the materials will become transparent. Plasma frequency $\left(\omega_{p}\right)$ values are calculated and summarized in Table 1, The high values of plasma frequency are attributed to the high values of the free carrier concentrations.

Further analysis of the refractive index can be made using a single term Sellmeier oscillator, hence, Wemple-Didomenico formula is modified to calculate the static optical index of refraction at infinite wavelength as follow [42]:

$$
\begin{aligned}
& \frac{n_{0}^{2}-1}{n^{2}-1}=1-\left(\frac{\lambda_{0}}{\lambda}\right)^{2} \\
& \frac{n_{0}^{2}-1}{n^{2}-1}=\frac{\lambda^{2}-\lambda_{0}^{2}}{\lambda^{2}}
\end{aligned}
$$

Where $\lambda_{0}$ is the average oscillator wavelength.

$$
\left(n^{2}-1\right)^{-1}=\frac{\lambda^{2}-\lambda_{0}^{2}}{\left(n_{0}^{2}-1\right) \lambda^{2}}=\frac{1}{\left(n_{0}^{2}-1\right)}-\frac{\lambda_{0}^{2}}{\left(n_{0}^{2}-1\right)} \frac{1}{\lambda^{2}}
$$


The dispersion equation in Eqn. (4) can be rewritten in terms of $\lambda$ by using $E=h \mathrm{c} / \lambda$, as follows:

$$
\left(n^{2}-1\right)^{-1}=\frac{E_{0}}{E_{d}}-\frac{(h c)^{2}}{E_{o} E_{d}} \frac{1}{\lambda^{2}}
$$

So, from Eqn. (10) and Eqn. (11), we can obtain:

$$
\frac{E_{0}}{E_{d}}=\frac{1}{n_{0}^{2}-1} \quad \text { and } \quad \frac{h^{2} c^{2}}{E_{0} E_{d}}=\frac{\lambda_{0}^{2}}{n_{0}^{2}-1}
$$

Hence, from Eqn. (12), we can deduce that:

$$
E_{0}=\frac{h c}{\lambda_{0}} \quad \text { and } \quad E_{d}=\frac{h c\left(n_{0}^{2}-1\right)}{\lambda_{0}}
$$

Thus Eqn. (13) can be rewritten in terms of average oscillator strength $\left(s_{0}\right)$ and average oscillator wavelength $\left(\lambda_{0}\right)$ as follows:

$$
n^{2}-1=\frac{s_{0} \lambda_{0}^{2} \lambda^{2}}{\lambda^{2}-\lambda_{0}^{2}} \quad \Rightarrow \quad\left(n^{2}-1\right)^{-1}=\frac{1}{s_{0} \lambda_{0}^{2}}-\frac{1}{s_{0}} \frac{1}{\lambda^{2}}
$$

Where, $s_{0}=\frac{\left(n_{0}^{2}-1\right)}{\lambda_{0}^{2}}$, thus, the values of $\left.s\right)$ and $\lambda_{0}$ can be calculate by using the values of $E_{0}$ and $n_{0}$ or by plotting $\left(n^{2}-1\right)^{-1}$ versus $\lambda^{-2}$ according to the Eqn.(14), as shown in Fig. 8. By knowing the slope and intercept of fitted curves of Fig. 8 the values of $s_{o}$ and $\lambda_{o}$ are calculated and listed in Table 1. It was observed that the values of $s_{o}$ and $\lambda_{o}$ which are calculated in different ways are matching to each other.

\section{Nonlinear optical parameters}

Nonlinear optics deals with the response of a material's nonlinear polarization to incident radiation. Determination of nonlinear optical parameters of materials is useful in the manufacture of frequency conversion and optical switching devices, which is an important part of integrated photonics. The calculation of the linear, nonlinear third optical susceptibilities $\left(\chi^{(1)} \& \chi^{(3)}\right)$ and the nonlinear refraction index $n_{2}$, of PVA/Cu nanocomposite samples are estimated based on Miller's rule using the following equations $[47,48]$.

$$
\begin{aligned}
& \chi^{(1)}=E_{d} / 4 \pi E_{0} \\
& \chi^{(3)}=A\left(\chi^{(1)}\right)^{4}
\end{aligned}
$$


Where $A$ is a constant and equals to $1.79 \times 10^{-10}$ esu. Hence, $\chi^{(3)}$ values which indicates if the $\mathrm{PVA} / \mathrm{Cu}$ nanocomposite samples are appropriate for optical switching and photonic applications can be calculated in terms of static index of refraction, $n_{o}$ as follow

$$
\begin{aligned}
\chi^{(3)} & =A\left(\frac{E_{d}}{4 \pi E_{0}}\right)^{4} \\
& =\frac{A}{(4 \pi)^{4}}\left(n_{0}^{2}-1\right)^{4}
\end{aligned}
$$

The nonlinear refractive index, $n_{2}$ also can be calculated using the following semi-empirical formula as follow [49].

$$
n_{2}=\frac{G}{E_{d g}^{4}}
$$

Where $\mathrm{G}=1.26 \times 10^{-9}$ [esu $\left.(\mathrm{eV})^{4}\right] . \quad$ The values of linear and non-linear optical parameters $\left(\chi^{(1)}\right.$, $\left.\chi^{(3)}, \mathrm{n}_{2}\right)$ of all samples are estimated and Tabulated in Table 1 . Values of $\left(\chi^{(1)}, \chi^{(3)}, \mathrm{n}_{2}\right)$ indicate that the studied PVA/Cu nanocomposite samples could be interesting candidates for use in applications of photonics, high-performance photoelectric conversion elements for fiber communications, optical power limiting and optical information processing [50].

\section{Optical Conductivity and optical dielectric constant}

The optical and electrical conductivities $\left(\sigma_{o p t} \& \sigma_{e}\right)$ of PVA/Cu nanocomposite samples can be calculated by the optical method using the following equations [51]

$$
\begin{gathered}
\sigma_{o p t}=\frac{\alpha n c}{4 \pi} \\
\sigma_{e}=\frac{2 \lambda \sigma_{o p t}}{\alpha}
\end{gathered}
$$

Fig. 9 displays the variation of both optical conductivity $\left(\sigma_{\mathrm{opt}}\right)$ and electrical conductivity $\left(\sigma_{\mathrm{e}}\right)$ against the wavelength. It is found that, the optical conductivity behaves in the same way as the variation of the absorption $(A)$ against wavelength, whereas, the electrical conductivity behaves in a different way compared to absorption $(A)$. Moreover, we note that the value of optical conductivity is in the order of $10^{12} \mathrm{sec}^{-1}$, which indicates that the PVA/Cu nanocomposite samples have high photo response, which makes the prepared nanocomposite samples are good 
candidate for use in information processing. The values of the electrical conductivity $\sim 10^{2} \mathrm{~S} / \mathrm{m}$ reveals the semiconducting nature of the PVA/Cu nanocomposite samples.

The correlation between optical and electrical behaviors within the materials determines the importance of the dielectric constants of those materials. The optical dielectric constant can be expressed as $\varepsilon^{*}(\omega)=\varepsilon^{\prime}(\omega)+\mathrm{i} \varepsilon^{\prime \prime}(\omega)$. The real and imaginary parts of the optical dielectric constant $\left(\varepsilon^{\prime} \& \varepsilon^{\prime \prime}\right)$ are related to the values of $n$ and $k$, as follow

$$
\begin{aligned}
\varepsilon^{\prime} & =n^{2}-k^{2} \\
\varepsilon^{\prime \prime} & =2 n k
\end{aligned}
$$

The refractive index $(n)$ and the extinction coefficient $(k)$ depend on the electronic polarization of ions, atoms or molecules of the substance exposed to an electric field. The electronic polarization occurs due to the displacement of the center of negative charges relative to the center of positive charges. The real part of the dielectric constant describes the amount that will impede the speed of light in the material, while the imaginary part shows the rate of dissipation of incident waves within the material, respectively. Fig. 10 (a\&b) depicts the variation of $\varepsilon^{\prime}$ and $\varepsilon^{\prime \prime}$ against the wavelength. It is observed that both $\varepsilon^{\prime}$ and $\varepsilon^{\prime \prime}$ change in the same pattern but the real part values are found to be much higher than those of the imaginary part. It is found that the values of $\varepsilon^{\prime}$ and $\varepsilon^{\prime \prime}$ is ranged from $\left(1.34 \times 10^{-4}\right.$ and $\left.0.52 \times 10^{-4}\right)$ of pure PVA to $\left(5.41 \times 10^{-4}\right.$ and $\left.22 \times 10^{-4}\right)$ for PVA/Cu Nanocomposite samples. The behavior of both $\varepsilon^{\prime}$ and $\varepsilon^{\prime \prime}$ contribute significantly to the design of electronic and optoelectronic applications.

Fig. 10c displays the dependence of the dielectric loss (tand $\left.\delta=\varepsilon^{\prime \prime} / \varepsilon^{\prime}\right)$ on the wavelength. The dielectric loss $(\tan \delta)$ is a key value for inferring the degradation level of the as-synthesized nanocomposites samples. The behavior of $\tan \delta$ showed a sharp decrease in the lower region of wavelength followed by nearly constant values particularly for pure PVA. Generally, the values of $\tan \delta$ of PVA/Cu Nanocomposite samples are higher than those of pure PVA. Therefore, we can say that CuNPs led to the formation of new levels of molecular dipole, as a point defect in the PVA matrix which in turn enhanced the dielectric loss of the composite samples.

\section{Conclusion}

XRD patterns displayed that sharp crystalline reflection of pure PVA at $2 \theta=19.74^{\circ}$ was affected after incorporating CuNPs indicating lower crystallinity of pure PVA. Moreover, two 
broad peaks at about $2 \theta=31.25^{\circ}$ and $49.82^{\circ}$ were observed and attributed to the (111) and (200) planes of the fcc structure of the CuNPs. FTIR analysis revealed that the absorption band was found at $1093 \mathrm{~cm}^{-1}$ which is a measure of the degree of crystallinity for PVA highly affected by the addition of CuNPs and it appeared as a broad band at $1077 \mathrm{~cm}^{-1}$ with a $16 \mathrm{~cm}^{-1}$ shift (red shift), indicating that the crystallinity of PVA is decreased. The absorption bands of both $\mathrm{CuO}$ and $\mathrm{Cu}_{2} \mathrm{O}$ nanostructures were observed in the observed in the range of $500-700 \mathrm{~cm}^{-1}$ of $\mathrm{PVA} / \mathrm{Cu}$ nanocomposites The optical properties have been investigated by the analysis of UV-Vis spectra. It was found that both indirect and direct energy gap were decreased from 4.71 to 3.50 $\mathrm{eV}$ and from 5.11 to $4.00 \mathrm{eV}$. This decrease in the optical band gap was attributed to the incorporation of CuNPs which increase the defects and disorder in PVA matrix. The linear and nonlinear optical parameters of the PVA/CuNPs composites were calculated and it was found that these parameters were improved by adding copper nanoparticles to the PVA matrix.

\section{References}

1. T. Fahmy, H. Elhendawi, W. B. Elsharkawy, F. M. Reicha, AC conductivity and dielectric relaxation of chitosan/poly(vinyl alcohol) biopolymer polyblend, Bull Mater Sci. 43, 243 (2020)

2. T. Fahmy, A. Sarhan, Z. M. Elqahtani, Structural and Optical Characterization of Thiourea-Poly (Vinyl Alcohol) Composites, Inter. J. of Eng. Res. and Techn. 13, 454-461 (2020).

3. T. Fahmy, Dielectric Relaxation and Electrical Conductivity Study in Thiourea- Doped Poly (Vinyl Alcohol), Inter. J. Polym. Mater 50, 109-127 (2001).

4. T. O. Owolabi, M. A. Abd Rahman, Modeling the Optical Properties of a Polyvinyl Alcohol-Based Composite Using a Particle Swarm Optimized Support Vector Regression Algorithm, Polymers. 13, 2697 (2021)

5. V. Gopishetty, I. Tokarev, S. Minko, Biocompatible stimuli-responsive hydrogel porous membranes via phase separation of a polyvinyl alcohol and Na-alginate intermolecular complex, J. Mater. Chem. 22, 19482-19487 (2012)

6. M. Kobayashi, Y.S. Chang and M. Oka, A two-year in vivo study of polyvinyl alcoholhydrogel (PVA-H) artificial meniscus, Biomaterials. 26, 3243-3248 (2005)

7. R.N. Rothon, Particulate Fillers for Polymers, Rapa Review Reports Summary, $1^{\text {st }}$ Ed. (Springer International Publishing Switzerland 2017), p. 195

8. T. Fahmy and M. T. Ahmed, Alternating -Current Conductivity and Dielectric Relaxation of Poly (Acrylonitrile-Butadiene-Styrene) Terpolymer Doped with Tetrabutylammonium Tetrafluoroborate, J. Polym. Mater. 20, 367-376 (2003)

9. P.K. Khanna, N. Singh, S. Charan, Synthesis of nanoparticles of anatase $\mathrm{TiO}_{2}$ and preparation of its optical transparent film in PVA, Mater. Lett. 61 4725- 4730 (2007)

10. A. Sarhan, T. Fahmy, Optical Properties, Antibacterial Activity, and Relaxation Behavior Investigation of Chitosan/Green Synthesized Silver Nanoparticles by 
Thermally Stimulated Depolarization Current Technique, Polymer Science, Series B. 63(5), 578-590 (2021)

11. T. Fahmy, A. Sarhan, Characterization and molecular dynamic studies of chitosan-iron complexes, Bull Mater Sci. 44, 142 (2021)

12. A. Kiesow, J.E Morris, C. Radehaus, A. Heilmann, Switching Behavior of Plasma Polymer Films Containing silver Nanoparticles, J. Appl. Phys. 94, 6988-6990 (2003)

13. Y. Min , M. Akbulut, K. Kristiansen K, Y. Golan , J. Israelachvili , The role of interparticle and external forces in nanoparticle assembly, Nature Mater. 7, 527-538 (2008)

14. T. C. S. Girisun and S. Dhanuskodi, Linear and nonlinear optical properties of tris thiourea zinc sulphate single crystals, Cryst. Res. Technol. 44, 1297-1302 (2009)

15. Z. Chai, X. Hu, F. Wang, X. Niu, J. Xie, and Q. Gong, "Ultrafast All - Optical Switching", Adv. Optical Mater. 5, 665-685 (2017)

16. A. Sacco, M. Gerosa, S. Bianco, L. Mercatelli, R. Fontana, L. Pezzati, L. Quaglio, C. F. Dirri, and A. O. M. Tucci, Dye - Sensitized Solar Cell for a Solar Concentrator System, Solar Energy. 125, 307-313 (2016)

17. G. I. Stegeman and R. A. Stegeman, Nonlinear Optics: Phenomena, Materials, and Devices, John Wiley and Sons, Inc., Publication (2012), p 78

18. Z. M. Wang and A. Neogi, (Eds.), Nanoscale Photonic and Optoelectronics, SpringerVerlag, Heidelberg (Springer-Verlag New York 2010), pp 231-240.

19. O. A Yeshchenko, I. MDmitruk, A. A Alexeenko. Y Losytskyy, M.Y Kotko, A. O Pinchuk. Size-dependent surface-plasmon-enhanced photoluminescence from silver nanoparticles embedded in silica. Phys. Rev. B 79, 235438 (2009)

20. D. M Schaadt, B. Feng, E. T Yu. Enhanced semiconductor optical absorption via surface plasmon excitation in metal nanoparticles. Appl. Phys. Lett. 86, 63106 (2005)

21. R. Ricciardi, F. Auriemma, C. Rosa, and F. Laupretre, X-ray Diffraction Analysis of Poly(vinyl alcohol) Hydrogels, Obtained by Freezing and Thawing Techniques, Macromolecules. 37, 1921-1927 (2004)

22. X. F Qian, J Yin, J. C Huang, Y. F Yang, X. X Guo, Z. K Zhu, The preparation and characterization of PVA/Ag $2 \mathrm{~S}$ nanocomposite. Materials chemistry and physics. 68 (1), 95-97 (2001)

23. J. Rozra, I. Saini, A. Sharma, N. Chandak, S. Aggarwal, R. Dhiman, P. K. Sharma, Cu nanoparticles induced structural, optical and electrical modification in PVA, Materials Chemistry and Physics. 134, 1121-1126 (2012)

24. F Wahid, H. S Wang, Y. S Lu, C. Zhong, L.Q Chu. Preparation, characterization and antibacterial applications of carboxymethyl chitosan/ $\mathrm{CuO}$ nanocomposite hydrogels. Int J Biol Macromol. 101, 690-695 (2017)

25. K. H. Tseng, H. C. Ke, H. C. Ku, Parameters and properties for the preparation of $\mathrm{Cu}$ nanocolloids containing polyvinyl alcohol using the electrical spark discharge method, Nanomaterials and Nanotechnology. 11, 1-8 (2021)

26. Y. Kobayashi and T. Sakuraba, Colloid Surf. A: Physico-chem. Eng. Aspects. 317, 756759 (2008)

27. Y. Luo, X. Jiang, W. Zhang W, X. Li. Effect of aluminium nitrate hydrate on the crystalline, thermal and mechanical properties of poly (vinyl alcohol) film. Polym. Polym. 23, 555-561 (2015) 
28. Y. L. Luo, Q. B. Wei, F. Xu, Y. S. Chen, L. H. Fan, and C. H. Zhang, Assembly, characterization and swelling kinetics of Ag nanoparticles in PDMAA-g-PVA hydrogel networks, Mater. Chem. Phys. 118, 329-336 (2009)

29. T. Fahmy, A. Sarhan, I. A. Elsayed, M. T. Ahmed, Effect of UV Irradiation on The Structure and Optical Properties of PVA/Cucl 2 , J. of Advances in Phys. 14(2), 53785387 (2018)

30. Y. L. Luo, L. L. Chen, F. Xu, Q. S. Feng, Fabrication and Characterization of Copper Nanoparticles in PVA/PAAm IPNs and Swelling of the Resulting Nanocomposites, Met. Mater. Int. 18(5), 899-908 (2012)

31. M.N.K. Chowdhury, M.D.H. Beg, Maksudur R. Khan, M.F. Mina, Synthesis of copper nanoparticles and their antimicrobial performances in natural fibres, Materials Letters. 98, 26-29 (2018)

32. K. Karthik, N. Victor Jaya, M. Kanagaraj, S. Arumugam, Temperature-dependent magnetic anomalies of CuO nanoparticles, Solid State Commun. 151, 564-568 (2011)

33. N. C.Angastiniotis , S. Christopoulos, K. C. Petallidou, A. M. Efstathiou, A. Othonos, L. Koutsokeras, Controlling the optical properties of nanostructured oxide-based polymer flms, Scientifc Reports. 11 (16009), 8 (2021)

34. T. Fahmy, A. Sarhan, I. A. Elsayed and H. G. Abelwahed, Optical Properties of Poly (Vinyl Chloride-co-Vinyl Acetate-co-2-Hydroxypropyl Acrylate)/ (AcrylonitrileButadiene-Styrene) Blends, Inter. J. of Eng., Research \&Tech. 11(9), 1405-1415 (2018)

35. T. Fahmy and M. T. Ahmed, Thermal induced structural change investigations in PVC/PEMA polymer blend, Polym. Testing. 20, 477 (2000)

36. S. Choudhary, Characterization of amorphous silica nanofiller effect on the structural, morphological, optical, thermal, dielectric and electrical properties of PVA-PVP blend based polymer nanocomposites for their flexible nanodielectric applications, J. Mater. Sci. Mater. Electron. 29, 10517-10534 (2018)

37. J. Park, Y. Kim, Effect of Shape of Silver Nanoplates on the Enhancement of Surface Plasmon Resonance (SPR) Signals. J. Nanosci. Nanotechnol. (2008), 8(10), 5026-5029.

38. C. Rhodes,S. Franzen, Surface plasmon resonance in conducting metal oxides. J. Appl. Phys. 100(054905), 4 (2006)

39. B. Xu, J. Zhou, Z. Ni, C. Zhang, and C. Lu, Synthesis of novel microencapsulated phase change materials with copper and copper oxide for solar energy storage and photothermal conversion, Solar Energy Materials and Solar Cells. 179, 87- 94 (2018)

40. Prasher, S.; Kumar, M.; Singh, S. Electrical and Optical Properties of O6+ Ion BeamIrradiated Polymers. Int. J. Polym. Anal. Charact. 19, 204-211 (2014)

41. Dahshan M, Introduction to Material Science and Engineering, 2nd Ed (Elsevier 2002).

42. S. H Wemple, Refractive-Index Behavior of Amorphous Semiconductors and Glasses, Phys. Rev B. 7, 3767-3777 (1973)

43. M. Tsai, S.H. Hsu, C.C. Ho, et al., High refractive index transparent nanocomposites prepared by in situ polymerization, J. Mater. Chem. C. Mater. Opt. Elec tron. Devices 2, 2251-2258 (2014)

44. B. Gündüz, Optical properties of poly [2-methoxy-5-(3' ,7' -dimethyloctyloxy)- 1,4phenylenevinylene] lightemitting polymer solutions: effects of molarities and solvents, Polym. Bull. 72, 3241-3267 (2015) 
45. S. H. Wemple, Jr. M. D. Domenico, Behavior of the Electronic Dielectric Constant in Covalent and Ionic Materials, Phys. Rev B. 3, 1338-1351 (1971)

46. T. S, Soliman, S. A, Vshivkov, Sh. I Elkalashy, Structural, linear and nonlinear optical properties of $\mathrm{Ni}$ nanoparticles - Polyvinyl alcohol nanocomposite films for optoelectronic applications, Optical Materials. 107, 110037 (2020)

47. L. Tichý, H. Ticha, P. Nagels, R. Callaerts, R. Mertens, M. Vlček, Optical properties of amorphous As-Se and Ge-As-Se thin films, Mater. Lett. 39, 122-128 (1999)

48. Li Chunfei, Nonlinear Optics Principles and Applications (Springer 2016), pp 177-200

49. H. Tichá, L. Tichý, Semiempirical relation between non-linear susceptibility (refractive index), linear refractive index and optical gap and its application to amorphous chalcogenides, J. Optoelectron. Adv. Mater. 4(2), 381-386 (2002)

50. R.W. Boyd, Nonlinear Optics, Academic Press (Elsevier 2020)

51. T.C.S. Girisun, S. Dhanuskodi, Linear and nonlinear optical properties of tris thiourea zinc sulphate single crystals, Cryst. Res. Technol. 44, 1297-1302 (2009)

Table 1: The optical parameters values of PVA/CuNPs composite samples.

\begin{tabular}{|c|c|c|c|c|c|}
\hline & Pure PVA & $\begin{array}{c}\text { PVA/CuNPs } \\
(3 \mathrm{~h})\end{array}$ & $\begin{array}{c}\text { PVA/CuNPs } \\
(6 \mathrm{~h})\end{array}$ & $\begin{array}{c}\text { PVA/CuNPs } \\
(72 \mathrm{~h})\end{array}$ & $\begin{array}{c}\mathrm{PVA} / \mathrm{CuNPs} \\
(120 \mathrm{~h})\end{array}$ \\
\hline Absorption edge, $(\mathrm{eV})$ & 4.91 & 3.93 & 3.87 & 3.85 & 3.81 \\
\hline Urbach tail, $(\mathrm{eV})$ & 0.39 & 0.58 & 0.452 & 0.51 & 0.48 \\
\hline Indirect bandgap energy, $\left(E_{i g}, \mathrm{eV}\right)$ & 4.71 & 3.77 & 3.72 & 3.69 & 3.50 \\
\hline Direct bandgap energy, $\left(E_{d g}, \mathrm{eV}\right)$ & 5.11 & 4.19 & 4.15 & 4.06 & 4.00 \\
\hline Carbon atoms (M) & 45 & 67 & 68 & 71 & 73 \\
\hline Lattice dielectric constant, $\varepsilon_{\mathrm{L}}$ & 12.87 & 14.10 & 18.04 & 16.93 & 20.91 \\
\hline$N / m^{*}\left(\mathrm{~m}^{-3} \mathrm{~kg}^{-1}\right)$ & $9.98 \times 10^{58}$ & $7.56 \times 10^{56}$ & $1.22 \times 10^{59}$ & $1.04 \times 10^{59}$ & $1.49 \times 10^{59}$ \\
\hline$N\left(\mathrm{~m}^{-3}\right)$ & $4.00 \times 10^{28}$ & $3.03 \times 10^{28}$ & $4.92 \times 10^{28}$ & $4.20 \times 10^{28}$ & $6.01 \times 10^{28}$ \\
\hline Plasma frequency, $\omega_{\mathrm{p}}(\mathrm{Hz})$ & $1.69 \times 10^{16}$ & $1.47 \times 10^{16}$ & $1.88 \times 10^{16}$ & $1.74 \times 10^{16}$ & $2.08 \times 10^{16}$ \\
\hline Oscillator energy $\left(E_{0}\right),(\mathrm{eV})$ & 3.42 & 4.46 & 4.01 & 4.15 & 3.86 \\
\hline Dispersion energy $\left(E_{d}\right),(\mathrm{eV})$ & 0.66 & 9.33 & 4.09 & 6.02 & 2.98 \\
\hline Static refractive index $\left(n_{0}\right)$ & 1.088 & 1.758 & 1.421 & 1.565 & 1.332 \\
\hline$M_{-1}$ & 0.428 & 1.446 & 1.010 & 1.203 & 0.879 \\
\hline$M_{-3},(\mathrm{eV})^{-2}$ & 0.033 & 0.072 & 0.062 & 0.069 & 0.059 \\
\hline Static dielectric constant $\left(\varepsilon_{s}\right)$ & 1.06 & 3.09 & 2.02 & 2.44 & 1.77 \\
\hline $\begin{array}{l}\text { Optical oscillator strength }(f) \\
(\mathrm{eV})^{2}\end{array}$ & 2.38 & 41.66 & 16.39 & 25 & 11.49 \\
\hline $\begin{array}{l}\text { *Average single oscillator } \\
\text { wavelength }\left(\lambda_{0}\right)(\mathrm{m})\end{array}$ & $3.44 \times 10^{-7}$ & $2.77 \times 10^{-7}$ & $3.09 \times 10^{-7}$ & $2.98 \times 10^{-7}$ & $3.21 \times 10^{-7}$ \\
\hline $\begin{array}{l}\text { *Average single oscillator strength } \\
\left(s_{0}\right)\left(\mathrm{m}^{-2}\right)\end{array}$ & $1.54 \times 10^{12}$ & $2.71 \times 10^{13}$ & $1.06 \times 10^{13}$ & $1.62 \times 10^{13}$ & $7.46 \times 10^{12}$ \\
\hline $\begin{array}{l}\text { ***Average single oscillator } \\
\text { wavelength }\left(\lambda_{0}\right)(\mathrm{m})\end{array}$ & $3.13 \times 10^{-7}$ & $2.67 \times 10^{-7}$ & $3.05 \times 10^{-7}$ & $2.83 \times 10^{-7}$ & $3.02 \times 10^{-7}$ \\
\hline $\begin{array}{ll}{ }^{* *} \text { Average single } & \text { oscillator } \\
\text { strength }\left(s_{0}\right)\left(\mathrm{m}^{-2}\right) & \end{array}$ & $7.46 \times 10^{12}$ & $3.23 \times 10^{13}$ & $1.21 \times 10^{13}$ & $2.32 \times 10^{13}$ & $1.32 \times 10^{13}$ \\
\hline Linear optical susceptibility $\chi^{(1)}$ & 0.014 & 0.1665 & 0.0812 & 0.1153 & 0.0615 \\
\hline $\begin{array}{l}\text { Third-order nonlinear optical } \\
\text { susceptibility } \chi^{(3)} \text { (e.s.u.) }\end{array}$ & $8.21 \times 10^{-18}$ & $1.37 \times 10^{-13}$ & $7.79 \times 10^{-15}$ & $3.17 \times 10^{-14}$ & $2.57 \times 10^{-15}$ \\
\hline $\begin{array}{l}\text { Nonlinear refractive index }\left(\mathrm{n}_{2}\right) \\
\text { (e.s.u) }\end{array}$ & $2.84 \times 10^{-16}$ & $2.95 \times 10^{-12}$ & $2.06 \times 10^{-13}$ & $7.64 \times 10^{-13}$ & $7.28 \times 10^{-14}$ \\
\hline
\end{tabular}

$\left.{ }^{*}\right)$ The values of $s_{o}$ and $\lambda_{o}$ are calculated using the values of $\mathrm{E}_{0}$ and $\mathrm{n}_{0}$.

$\left.{ }^{* *}\right)$ The values of $s_{o}$ and $\lambda_{o}$ are calculated experimentally from $\left(n^{2}-1\right)^{-1}$ vs $\lambda^{2}$. 


\section{X-ray diffraction}
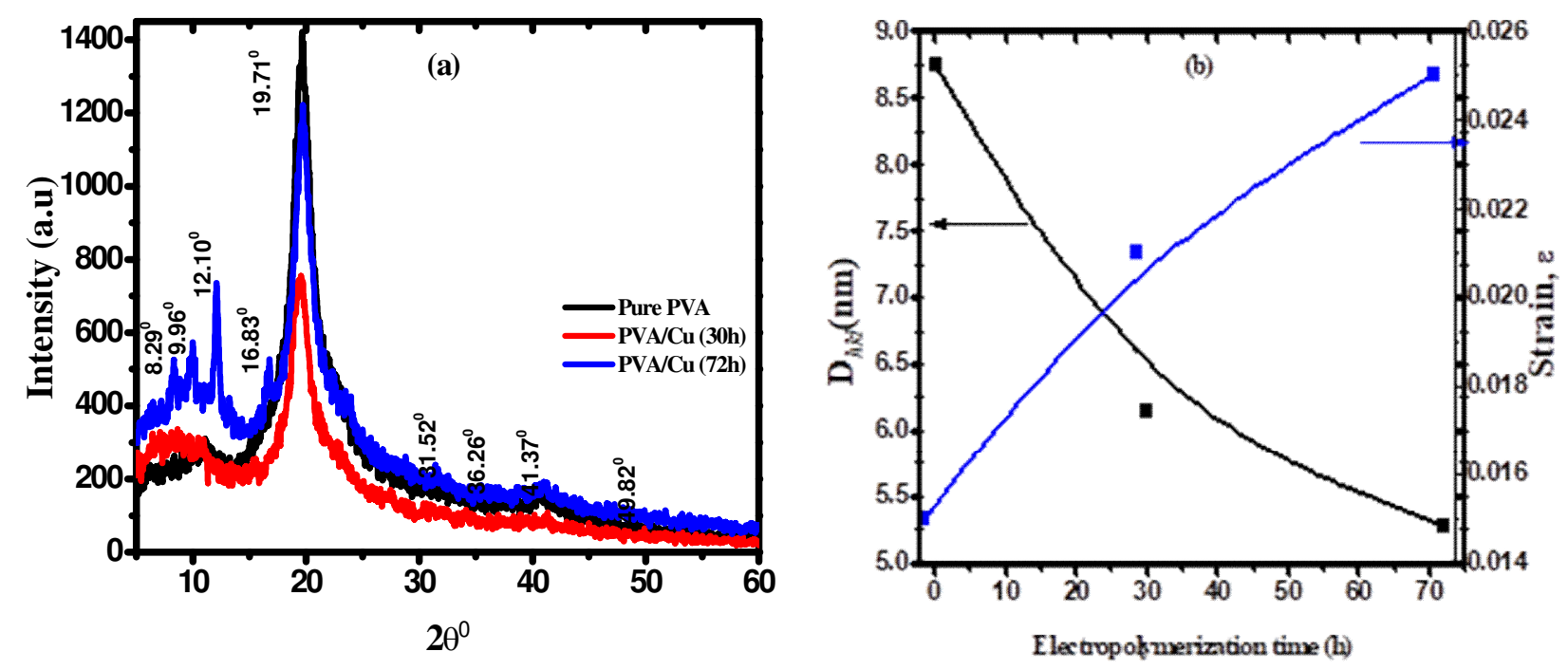

Fig 1. a) XRD pattern of of pure PVA and PVA/CuNPs composite samples. b) Crystallite size and internal strain against the electropolymerization time. (All Figure plotted using OriginProlab 8 Program)

\section{FTIR Spectroscopy}

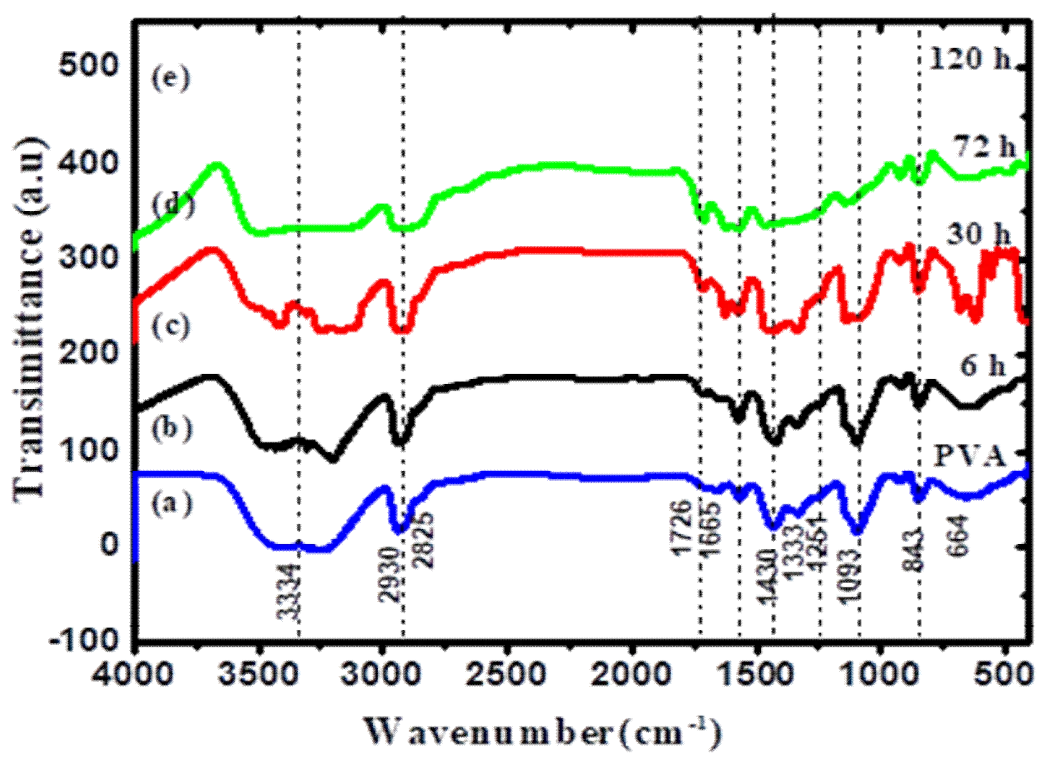

Fig 2. FTIR spectra of pure PVA and PVA/CuNPs composite samples. 

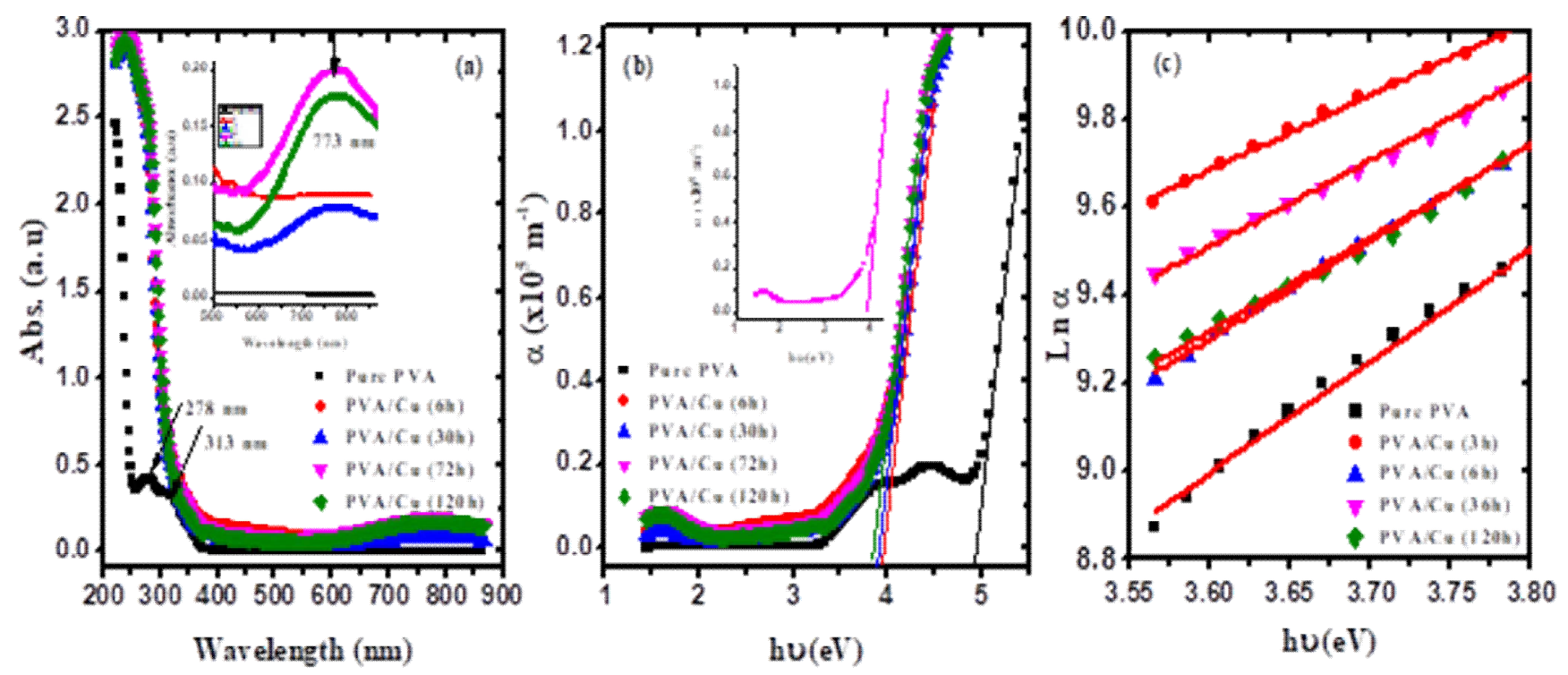

Fig 3. a) The absorption versus wavelength b) The absorption versus wavelength photon energy c) Ln $\alpha$ versus $h v$.
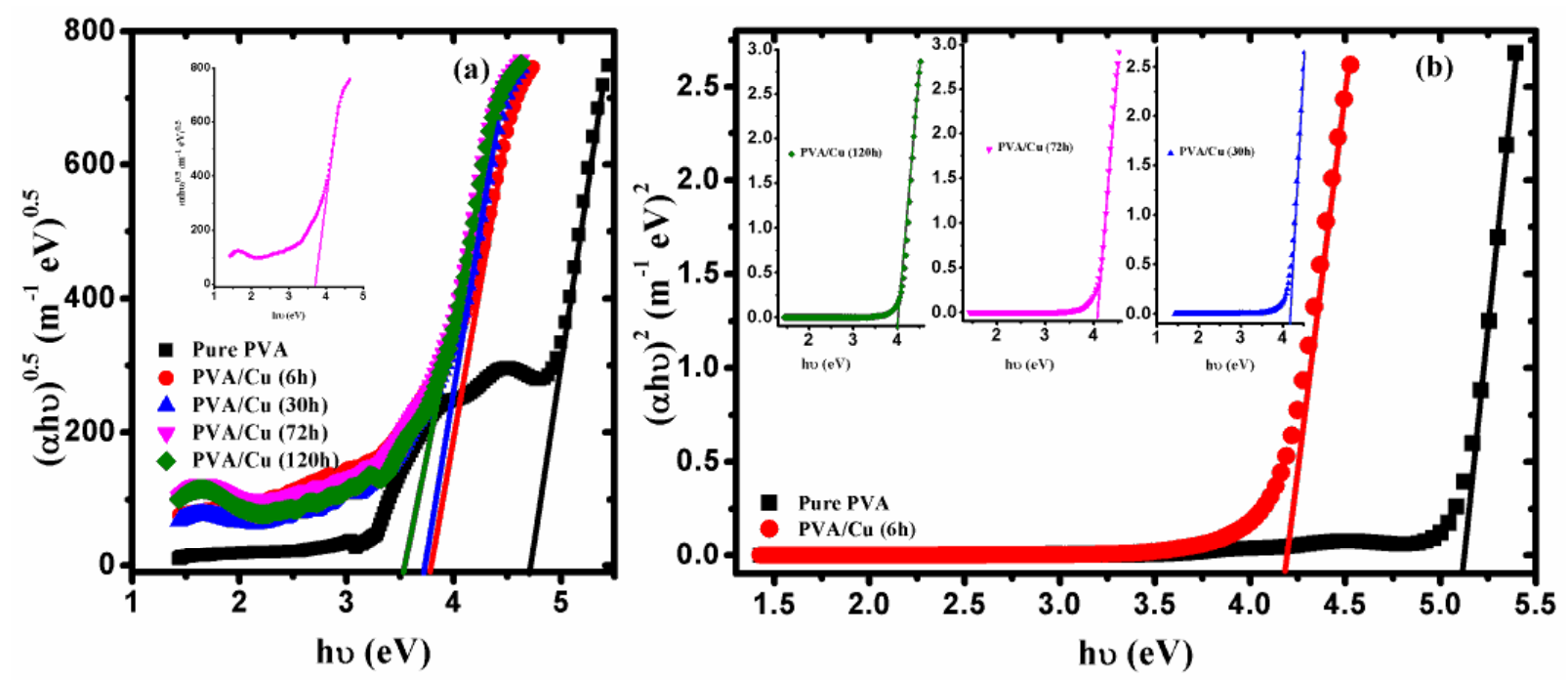

Fig 4. a) $(\alpha h v)^{0.5}$ b) $(\alpha h v)^{2}$ versus the photon energy $(h v)$. 


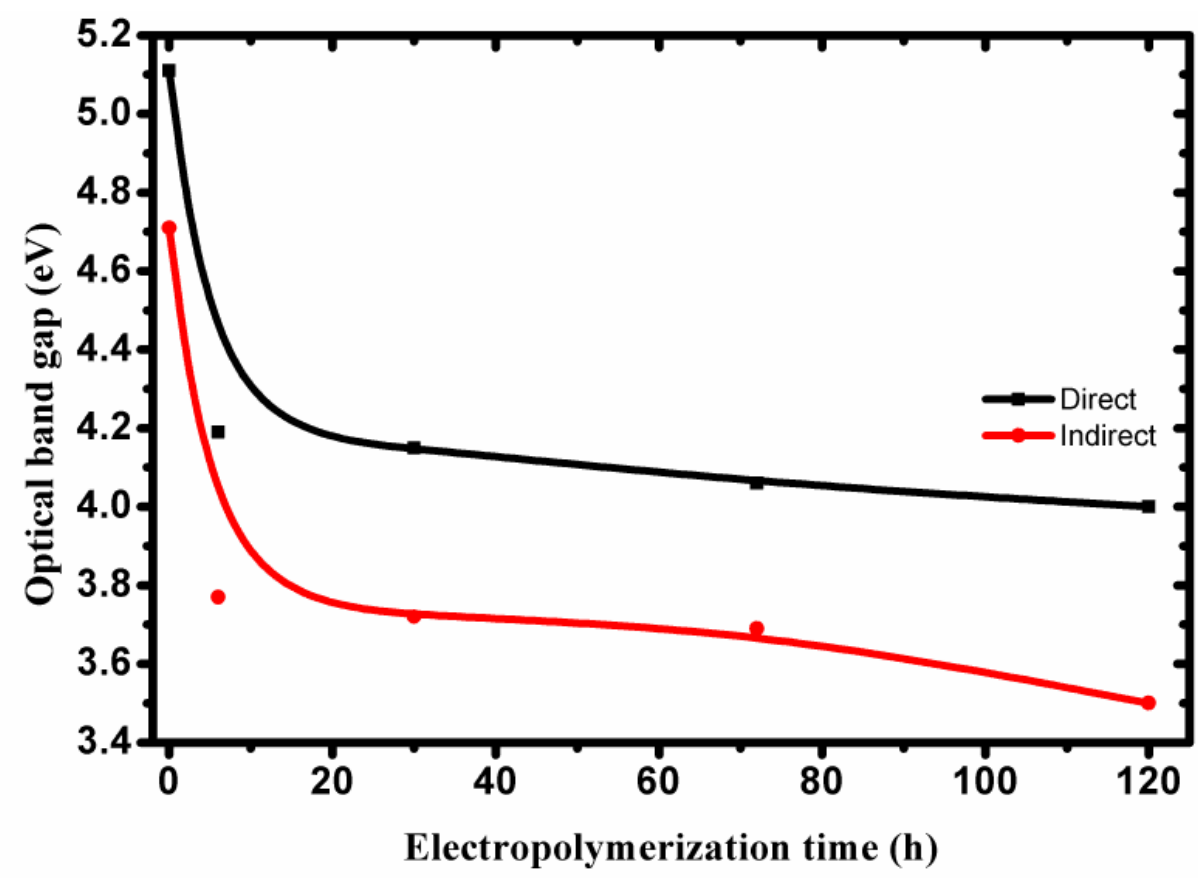

Fig 5. The variation of direct and indirect optical bandgap versus the electropolymerization time.
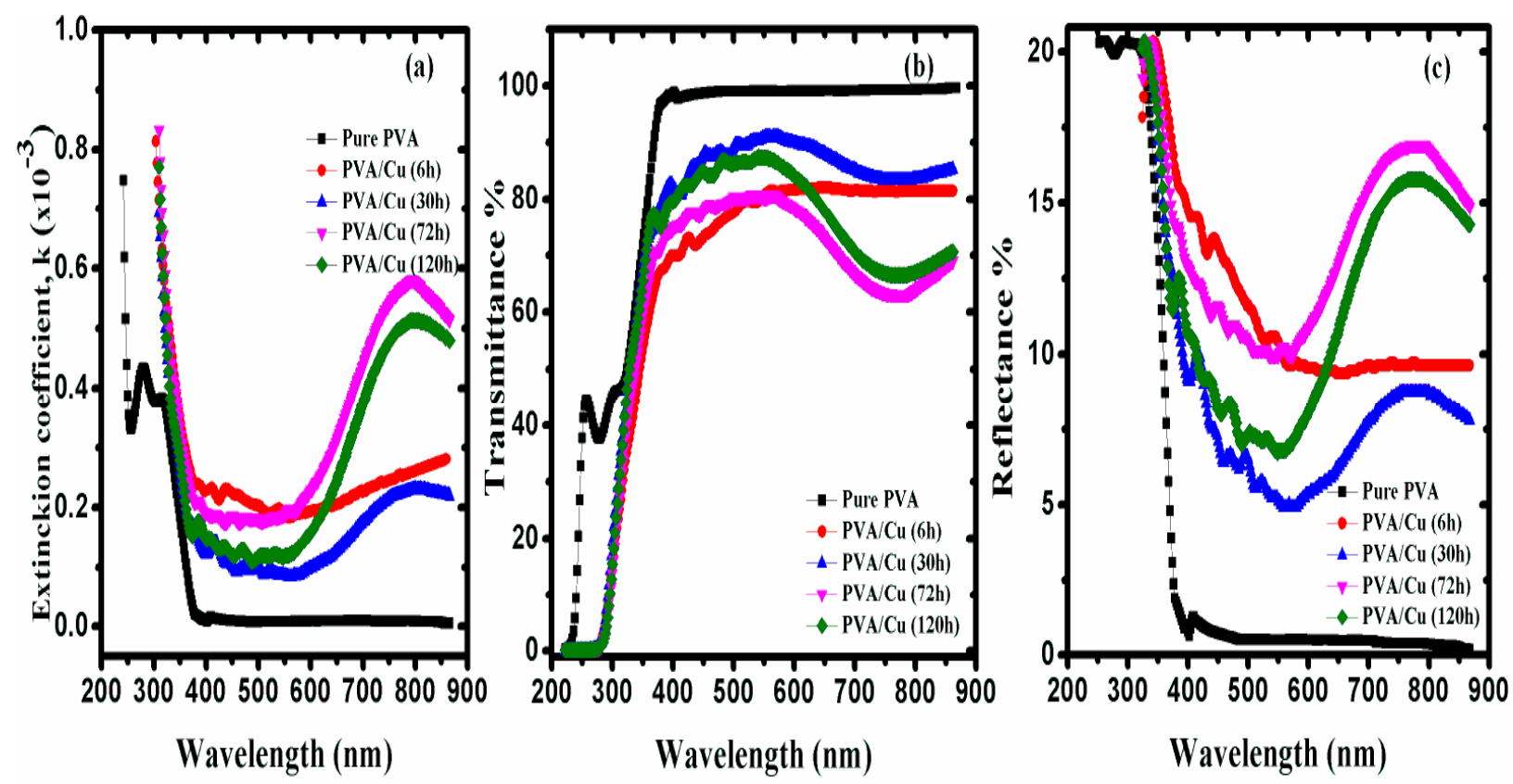

Fig 6. a) The extinction coefficient b) Transmittance and c) Reflectance versus the wavelength. 

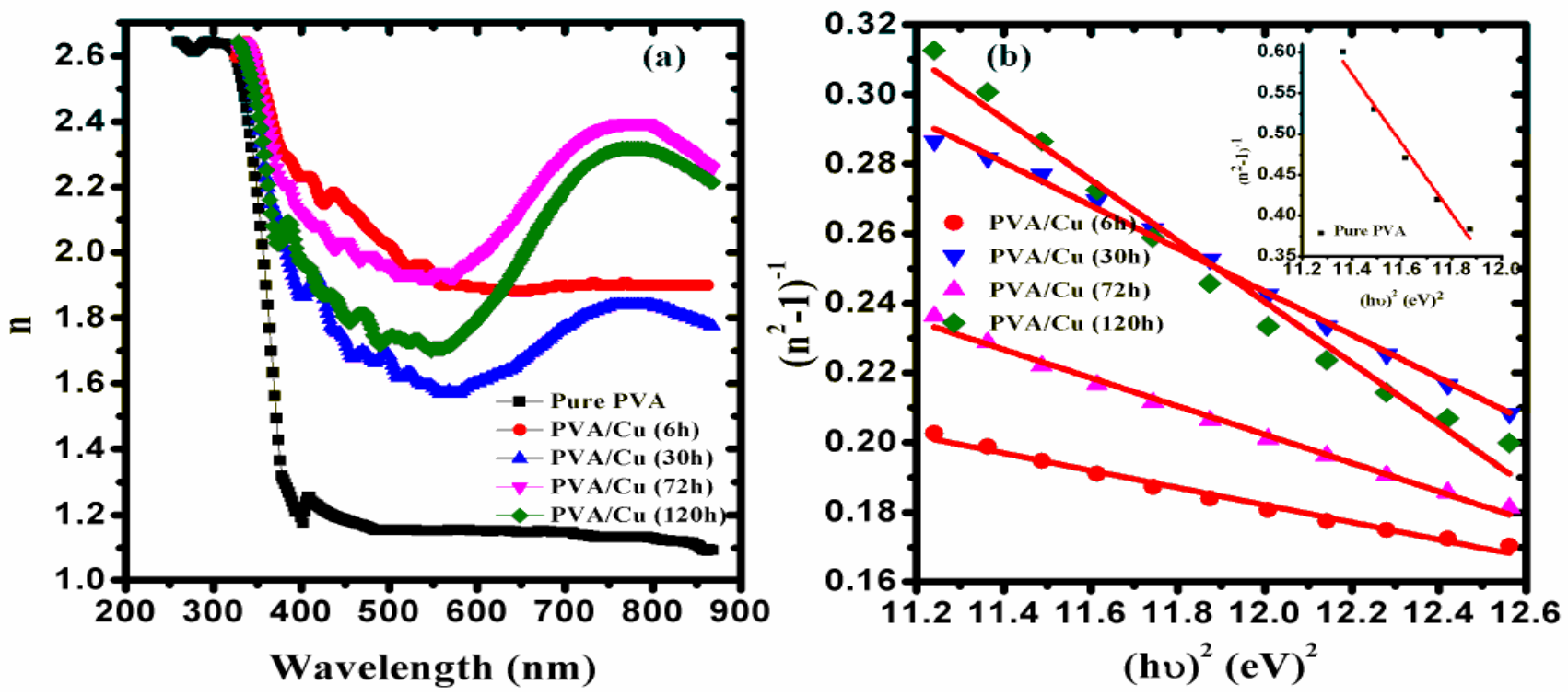

Fig 7. a) variation of the refractive index (n) against wavelength b) $\left(n^{2}-1\right)^{-1}$ versus $(h v)^{2}$.
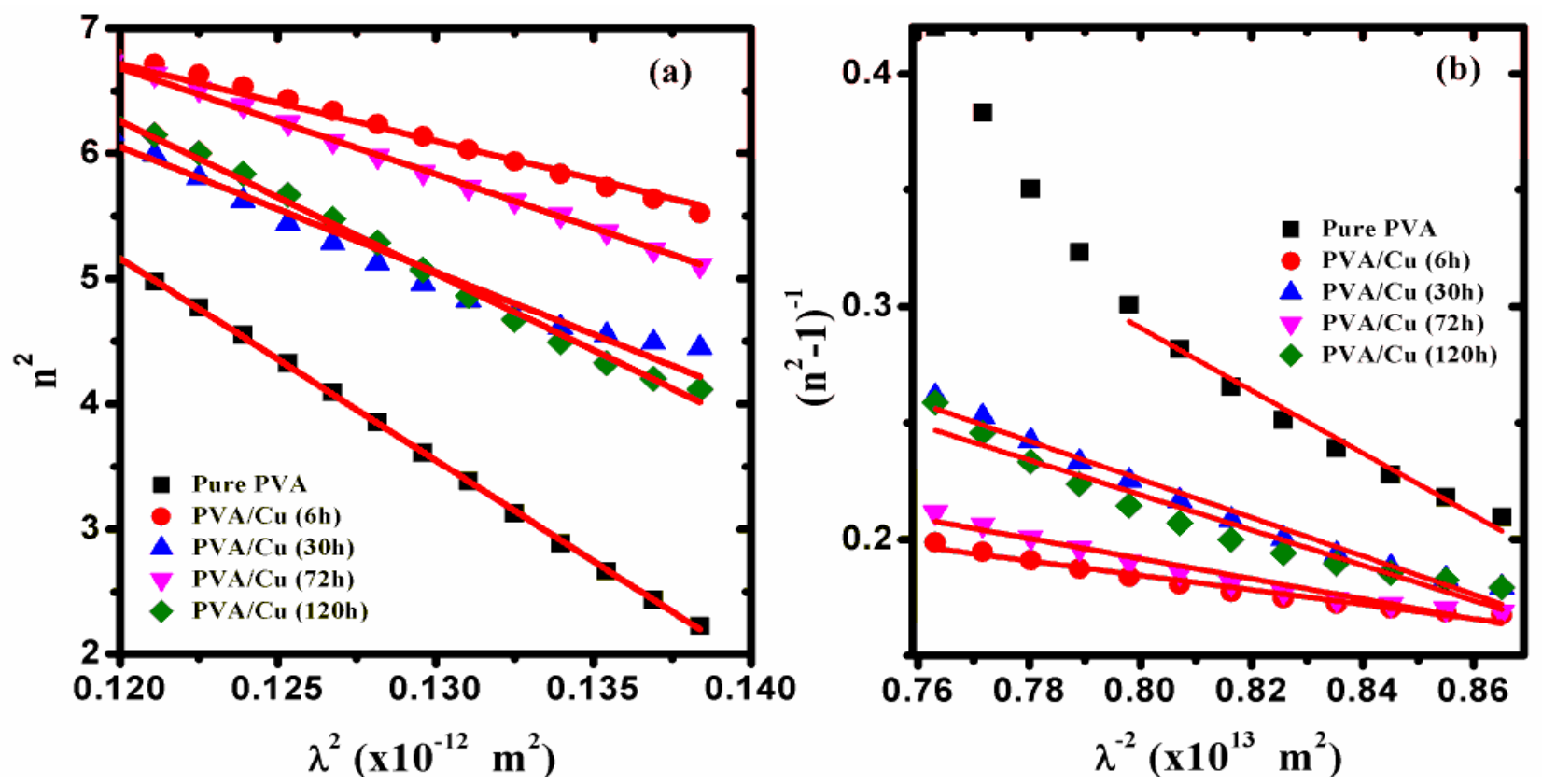

Fig 8. a) variation of the refractive index square $\left(n^{2}\right)$ against wavelength square

b) $\left(\mathbf{n}^{2}-1\right)^{-1}$ versus $(\lambda)^{-2}$. 

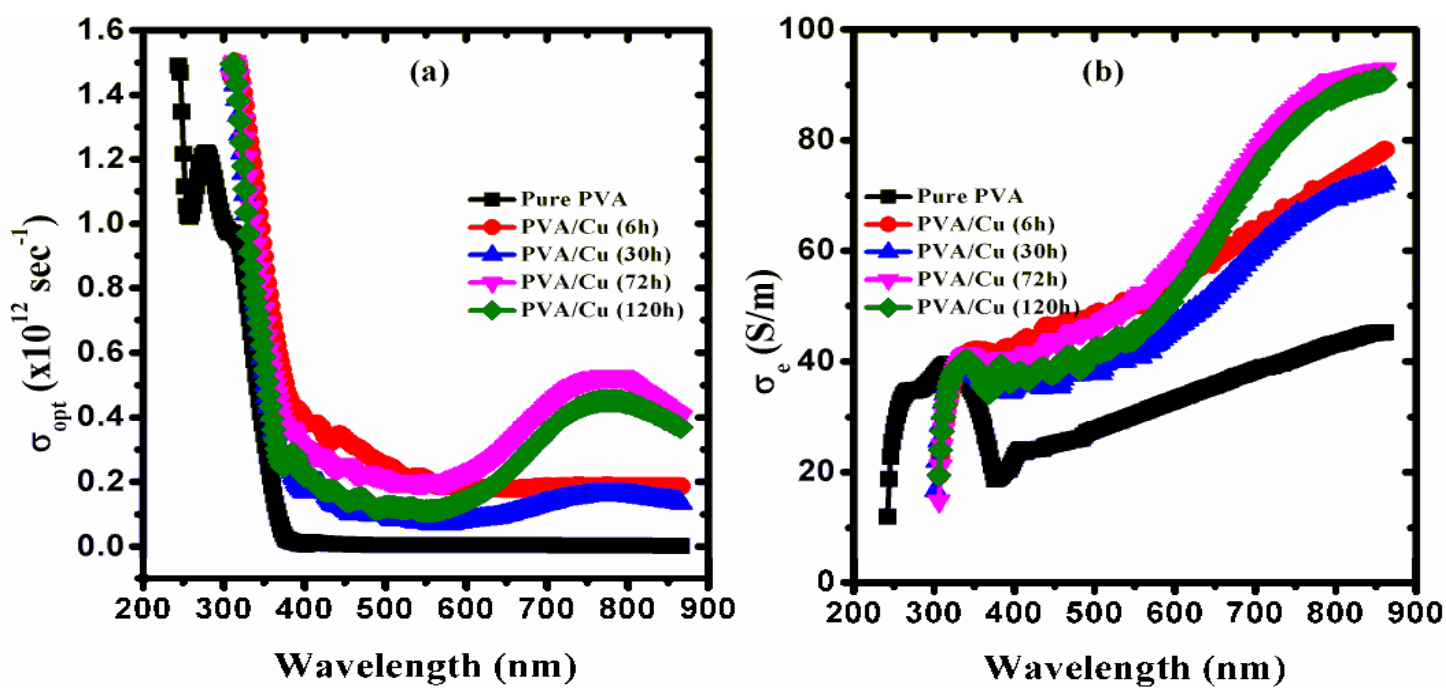

Fig 9. The variation of a) optical conductivity and b) electrical conductivity versus the wavelength.
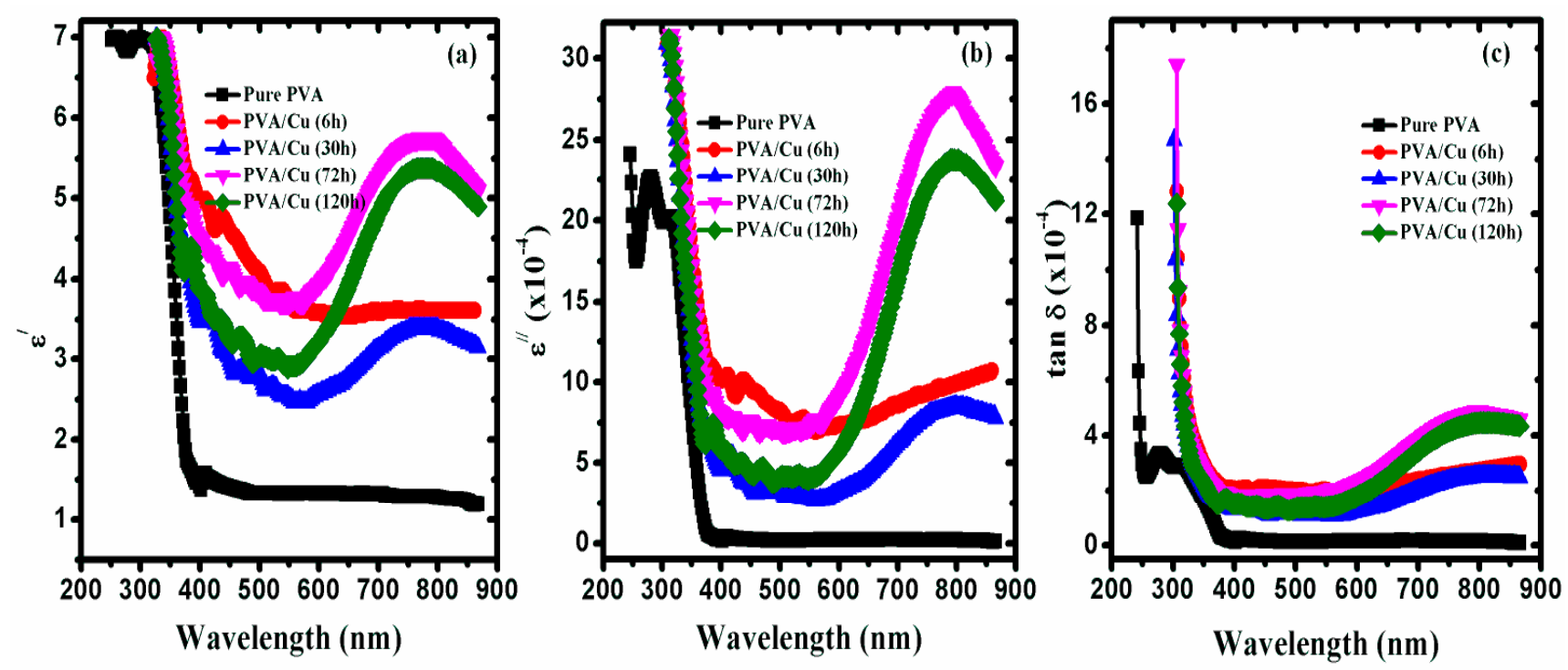

Fig 10. The variation of $\varepsilon^{\prime}, \varepsilon^{\prime \prime}$ and $\tan \delta$ versus the wavelength. 